\title{
Report
}

\section{The 7th Asian Symposium on Visualization}

\author{
Winoto, S.H.* \\ * Department of Mechanical Engineering, National University of Singapore, \\ 10 Kent Ridge Crescent, Singapore 119260, Singapore. \\ Abstract : The 7th Asian Symposium on Visualization (7ASV) was successfully held in \\ Singapore from $3^{\text {rd }}$ to $7^{\text {th }}$ November 2003 . This event was originally scheduled from $26^{\text {th }}$ to $30^{\text {th }}$ \\ May 2003, but had to be postponed because of the outbreak of SARS (Severe Acute Respiratory \\ Syndrome) in some parts of the world. A total number of 122 participants attended the \\ Symposium of which, 107 were foreign participants from 16 countries (excluding Singapore) \\ worldwide. There were 104 papers covering broad range of topics presented at the Symposium \\ which were delivered in 2 x 7 long sessions, and 9 keynote papers.
}

Keywords : Flow Visualization.

\section{Introduction}

The $7^{\text {th }}$ Asian Symposium on Visualization (7ASV) was successfully held from $3^{\text {rd }}$ to $7^{\text {th }}$ November 2003 at the Faculty of Engineering, National University of Singapore (NUS). This event was originally scheduled from $26^{\text {th }}$ to $30^{\text {th }}$ May 2003 , but had to be postponed because of the outbreak of SARS (Severe Acute Respiratory Syndrome) in some parts of the world.

This Symposium is the latest in the series of Asian Symposia of Visualization, which was first held in Beijing, China (1988) and successively in Hangzhou, China (1992), Chiba, Japan (1994), Beijing, China (1996), Bali, Indonesia (1999) and Pusan, Korea (2001).

The main aim of the Symposia is to provide a forum for researchers and practitioners to communicate and exchange information in the field of visualization applied over a wide range of disciplines which utilizes this technique such as, fluid dynamics, acoustics, aerodynamics, biomedical science, chemical engineering, civil engineering, environmental science, medical imaging, metallurgy, meteorology, oceanography, solid mechanics, sports science, and many others.

A total number of 122 participants attended the 7ASV of which, 107 were foreign participants from 16 countries (excluding Singapore) worldwide. 104 papers covering a broad range of topics and visualization techniques were presented at the 7ASV in $2 \times 7$ long sessions, and 9 keynote papers by distinguished speakers from various parts of the world, were delivered.

\section{Opening Ceremony}

The Opening Ceremony of the 7ASV was held at Lecture Theatre 1 in the NUS Faculty of Engineering in the morning of Tuesday, $4^{\text {th }}$ November 2003. Prof. Shih Choon Fong, the NUS President and Vice-Chancellor was the Guest of Honour at the Opening Ceremony which was also attended by Dr. Lock Kai Sang, President of Institution of Engineers, Singapore (IES) and Prof. 
Seeram Ramakrishna, Dean of NUS Faculty of Engineering.

Prof. S.H. Winoto, the Chairman of the 7ASV Organizing Committee welcome all the 7ASV delegates and thanked them for their support. Prof. Y. Nakayama, an initiator of the ASV series gave a brief account on the history of ASV. Prof. Shih Choon Fong delivered a brief message and then formally opened the 7ASV.

The Opening Ceremony was then immediately followed by the first Keynote Lecture which was delivered by Prof. Naoki Suzuki of Institute of High Dimensional Medical Imaging, Japan. The details of all the Keynote Lectures are given in the following.

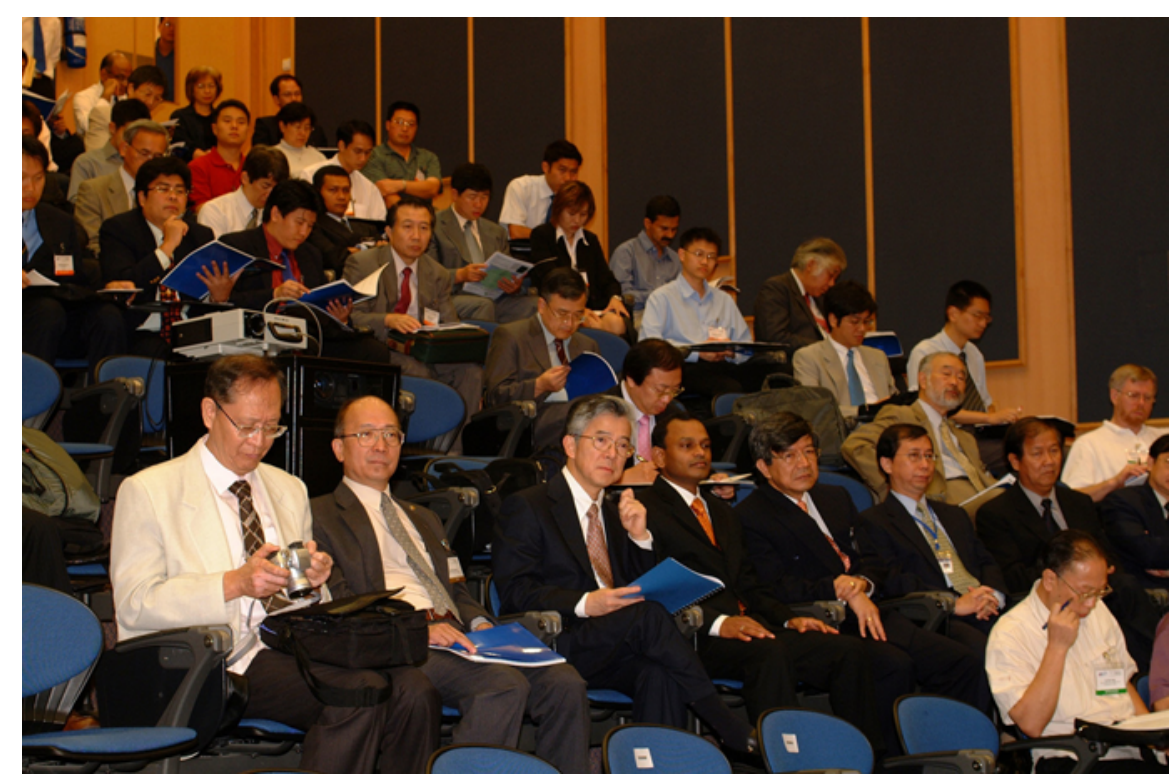

Fig. 1. Some participants at the 7ASV Opening Ceremony.

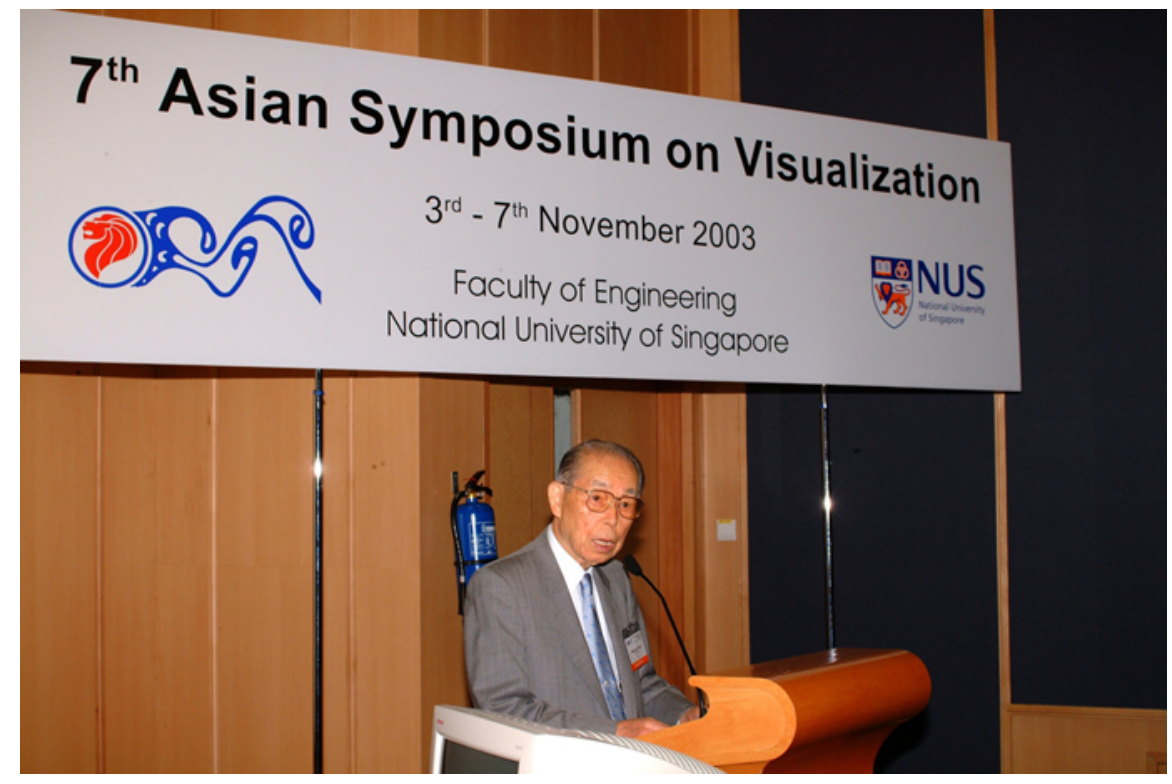

Fig. 2. Prof. Yasuki Nakayama, an initiator of the ASV series, delivering his address at the 7ASV Opening Ceremony. 


\section{Keynote Lectures}

1. Prof. Naoki SUZUKI of Institute of High Dimensional Medical Imaging, Japan:

"Visualization of Skeletal and Muscular Dynamics of Human Body

Locomotion Using $4 D$ Imaging".

2. Prof. Takami YAMAGUCHI of Tohoku University, Japan:

"Computational Visualization of the Blood Flow for the Application to Clinical Cardiovascular Medicine".

3. Prof. KIM Kyung Chun of Pusan National University, Korea

"PIV Application to Unsteady Three-Dimensional Flows".

(which was co-authored by Prof. YOO Jung Yul of Seoul National University, Korea).

4. Prof. Lorenz W. SIGURDSON of University of Alberta, Canada:

"Flow Visualization in Turbulent Large-Scale Structure and Flow Control Research".

5. Prof. Norman J. ZABUSKY of Rutgers University, USA:

"Science and Art of Fluid Motion".

6. Prof. Viktor V. KOZLOV of Institute of Theoretical and Applied Mechanics, Novosibirsk, Russia:

"Flow Visualization in Studies on the Origin of Turbulence in Near-Wall Flows".

7. Prof. Takeharu GOJI ETOH of Kinki University, Japan:

"Innovative High-speed Video Cameras".

8. Prof. LE Jia Ling of China Aerodynamics Research and Development Center (CARDC), China: "Some Progress in Research and Application of Computational Flow Imaging".

9. Prof. Ho Chih-Ming of University of California, Los Angeles, USA:

"Visualizing Heterogeneous Flows in Micro Fluidic Devices".

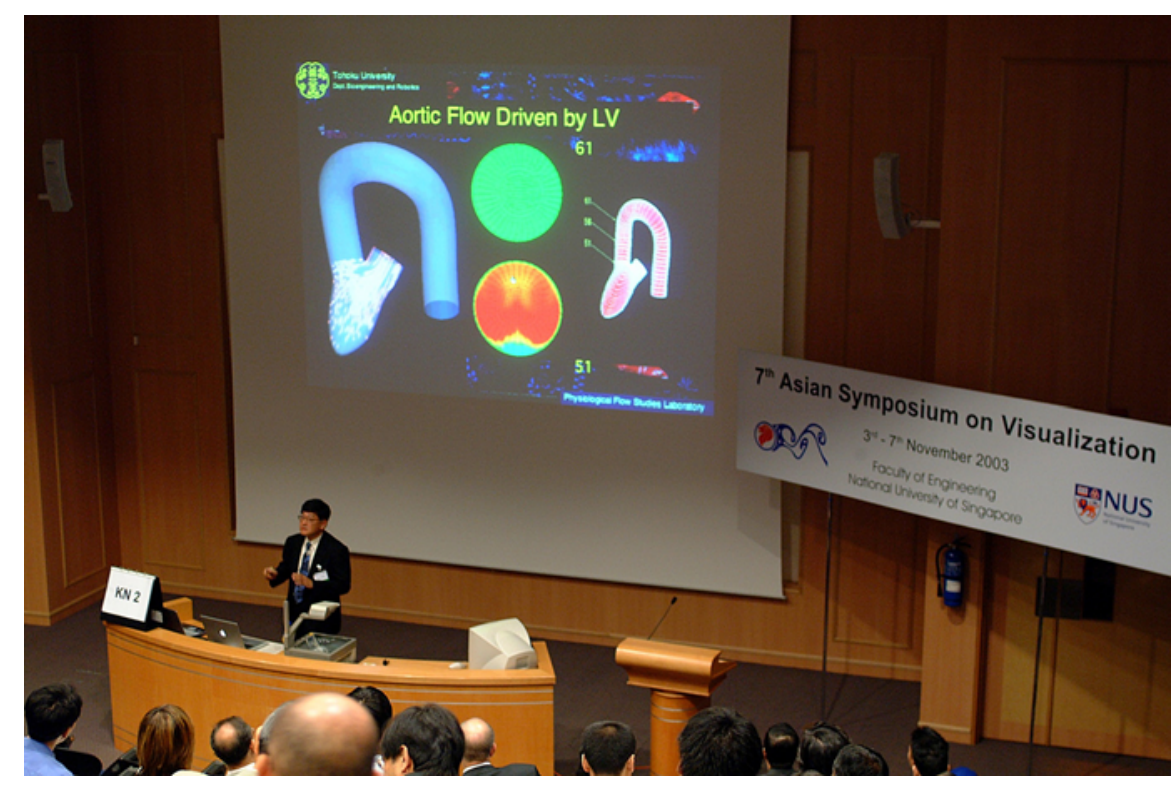

Fig. 3. Prof. Takami Yamaguchi delivering his keynote lecture. 


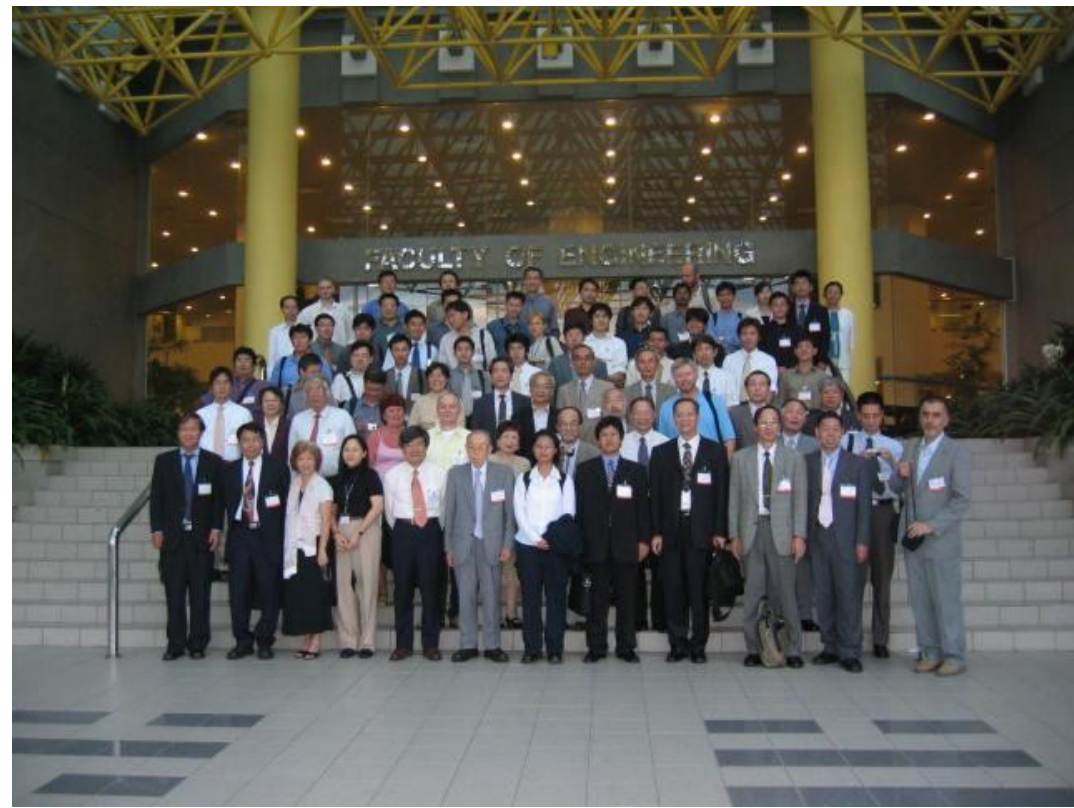

Fig. 4. Group photograph of 7ASV participants.

\section{Technical Papers}

A total of 104 technical papers were presented at the 7ASV in 2 parallel $\mathrm{x} 7$ long sessions. The presentation time for each paper is 15 minutes. The papers cover a broad range of topics as well as visualization techniques. The topics covered include acoustics, aerodynamics, bio-fluid mechanics, environmental fluid mechanics, fluid machinery, flow past cylinders and sports balls, internal combustion engines, jet flows, micro-systems, vortex flows, etc.

The visualization techniques reported in the papers are mainly experimental qualitative techniques using tracers, Particle Image Velocimetry (PIV) and numerical (computational) methods

All the papers and the keynote papers are published in the Proceedings of the 7th Asian Symposium on Visualization in the form of CD ROM (ISBN: 981-04-9686-9) which was edited by S.H. Winoto and W.K. Chan.

A booklet which contains the Programme of 7ASV and Abstracts of all papers, as well as all the necessary information was also distributed to the participants together with the Proceedings.

\section{Social Programs and Technical Visits}

A Welcome Dinner for the participants was held on the evening of $4^{\text {th }}$ November 2003, followed by "Singapore by Night Tour" which included a river cruise to see the Merlion - with the head of a lion and the body of a fish, which represents both the ancient and the modern Singapore. The final destination of the tour was the Raffles Hotel, which is Singapore's oldest and most prestigious hotel with the grandeur of colonial setting.

The meeting of the 7ASV International Steering Committee was held on the evening of $5^{\text {th }}$ November 2003 followed by a Chinese Set Dinner at the Stamford Restaurant, Kent Ridge Guild House. Since this evening was free for the delegates, some optional tours had been arranged to either Singapore Night Safari, which is the world's first and only Night Safari, or to join Chinese Junk cum Dinner Cruise around Singapore's southern islands. A free unguided tour to Esplanade Theatres by the bay, and Singapore's answer to Sydney's Opera House was also suggested to the delegates. 


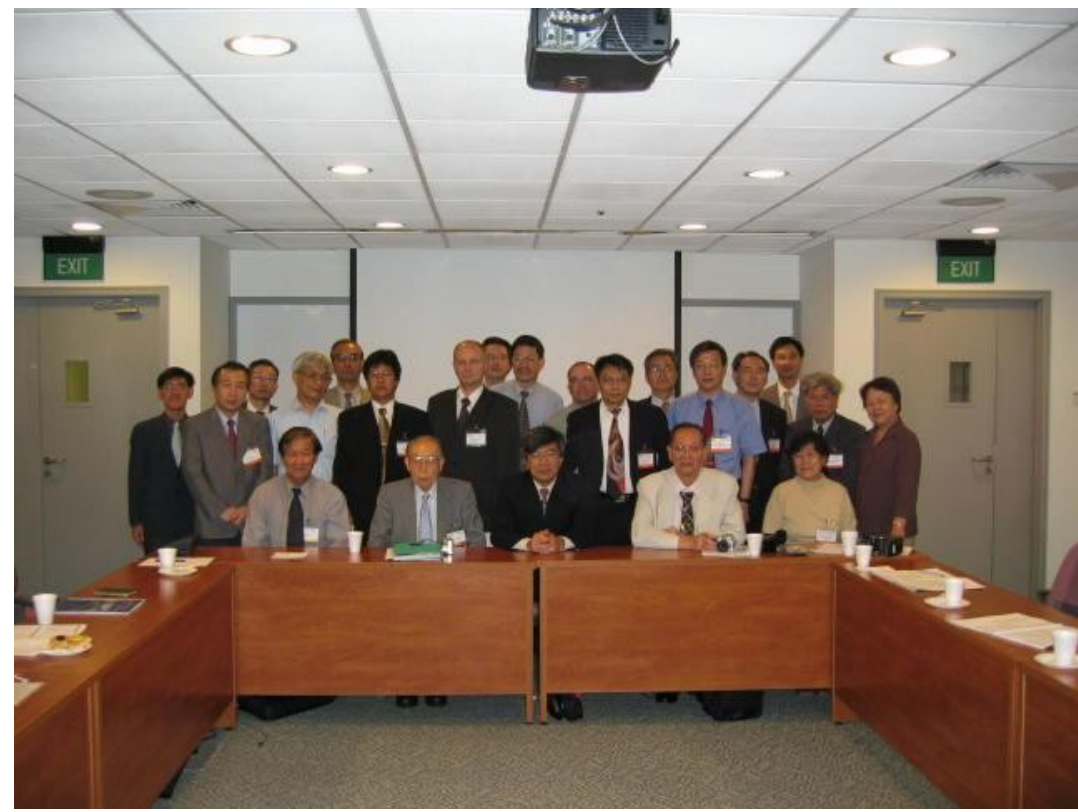

Fig. 5. 7ASV International Steering Committee meeting.

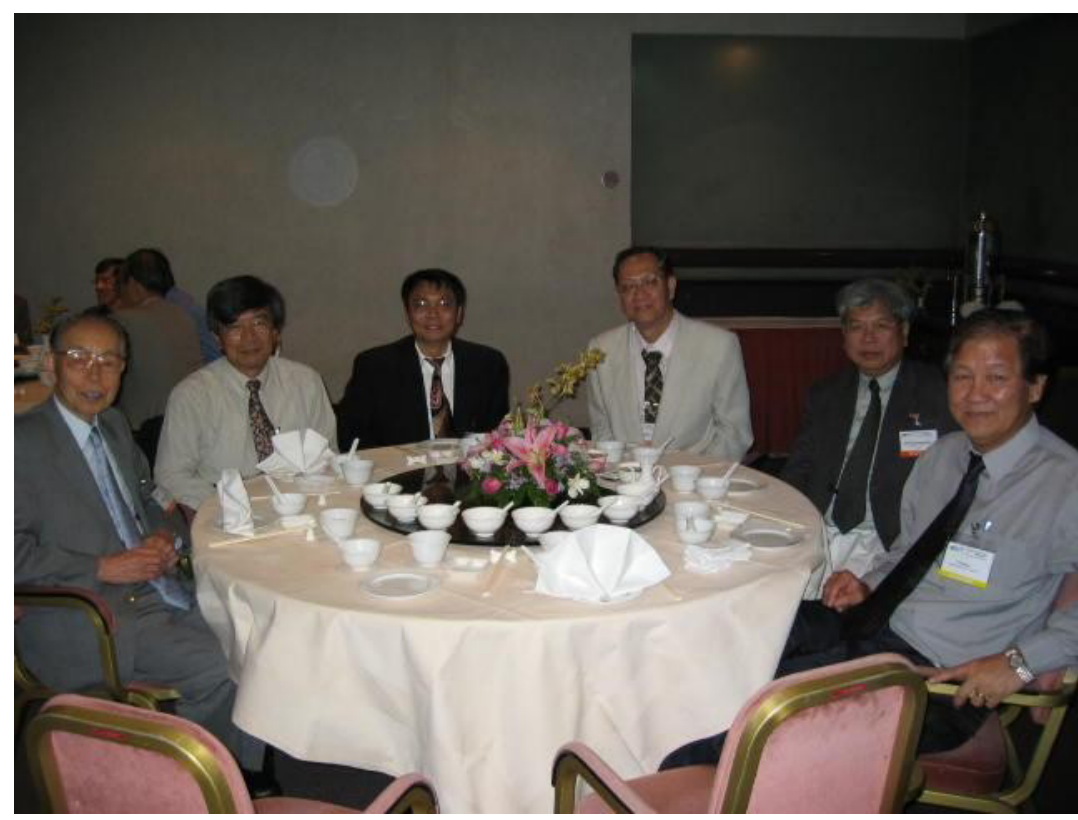

Fig. 6. 7ASV International Steering Committee dinner.

The completion of all technical sessions on $6^{\text {th }}$ November 2003 was followed by a Conference Banquet at the Raffles Marina (a yacht club) where delegates and their spouses could socially interact over a sumptuous buffet spread of international menu, and say good-bye.

On $7^{\text {th }}$ November 2003, the last day of 7ASV, technical tours were organized to: 1) NEWater Plant where the production of NEWater using the operation of advanced membrane and ultraviolet technologies was demonstrated, and 2) Institute of High Performance Computing (IHPC) at Singapore Science Park II where delegates were briefed on the Research Programs at IHPC before they were brought a laboratory to experience virtual realities. 


\section{Next Symposia}

The $8^{\text {th }}$ Asian Symposium on Visualization (8ASV) will be held on May 23 - 27, 2005 in Chiangmai, Thailand, under the leadership of Prof. B. Suwantragul of King Mongkut's University of Technology Thonburi. For further information, please contact the 8ASV Secretariat (Fax: (66) 24279633; Email: icec@kmutt.ac.th).

The $9^{\text {th }}$ Asian Symposium on Visualization will be held in June 2007 in Hong Kong, China.

\section{Author Profile}

S.H. Winoto: He obtained a Ph.D. from Imperial College, London in 1980 and joined the National
University of Singapore in the same year as a Lecturer. He subsequently became Senior Lecturer and
Associate Professor. He was a Visiting Professor at Georgia Institute of Technology and University of
Southern California (1988-89). He has been involved in organizing some international meetings in
Singapore and he is currently a Member of the International Advisory Committees of many
international conferences/symposia. He was twice elected to be the Chairman of the Singapore Section
of the American Society of Mechanical Engineers (ASME). He also served as the Chairman of Asia-
Pacific Zone of ASME Region XIII (1999-2001), and a Member of ASME Nominating Committee (2002-
04). His research interests include boundary layer flows and flow visualizations.

